\title{
Synthesis of bioluminescent gold nanoparticle-luciferase hybrid systems for technological applications
}

\author{
Elisângela Belleti ${ }^{1}$. Vanessa R. Bevilaqua ${ }^{2}$. Adrianne M. M. Brito ${ }^{1}$ • Diego A. Modesto ${ }^{1}$ - Alexandre J. C. Lanfredi ${ }^{1}$. \\ Vadim R. Viviani $^{1,3} \cdot$ Iseli L. Nantes-Cardoso ${ }^{1}$ (i)
}

Received: 11 August 2021 / Accepted: 27 September 2021 / Published online: 6 October 2021

(c) The Author(s), under exclusive licence to European Photochemistry Association, European Society for Photobiology 2021

\begin{abstract}
Bioluminescent gold nanoparticles (AuNPs) were synthesized in situ using dithiol-terminated polyethylene glycol $\left(\mathrm{PEG}(\mathrm{SH})_{2}\right)$ as reducer and stabilizing agents. Hybrid $\mathrm{Au} / \mathrm{F}_{3} \mathrm{O}_{4}$ nanoparticles were also produced in a variation of synthesis, and both types of nanostructures had the polymer capping replaced by L-cysteine (Cys). The four types of nanoparticles, $\mathrm{PEG}(\mathrm{SH})_{2} \mathrm{AuNPs}$, $\mathrm{PEG}(\mathrm{SH})_{2} \mathrm{Au} / \mathrm{F}_{3} \mathrm{O}_{4} \mathrm{NPs}$, CysAuNPs, and $\mathrm{CysAu} / \mathrm{F}_{3} \mathrm{O}_{4} \mathrm{NPs}$ were associated with purified recombinant Pyrearinus termitilluminans green emitting click beetle luciferase (PyLuc) and Phrixotrix hirtus (RELuc) red-emitting railroad worm luciferase. Enzyme association with $\mathrm{PEG}(\mathrm{SH})_{2}$ was also investigated as a control. Luciferases were chosen because they catalyze bioluminescent reactions used in a wide range of bioanalytical applications, including ATP assays, gene reporting, highthroughput screening, bioluminescence imaging, biosensors and other bioluminescence-based assays. The immobilization of PyLuc and RELuc promoted partial suppression of the enzyme luminescence activity in a functionalization-dependent way. Association of PyLuc and RELuc with AuNPs increased the enzyme operational stability in relation to the free enzyme, as evidenced by the luminescence intensity from 0 to $7 \mathrm{~h}$ after substrate addition. The stability of the immobilized enzymes was also functionalization-dependent and the association with CysAuNPs was the condition that combined more sustained luminescent activity with a low degree of luminescence quenching. The higher enzymatic stability and sustained luminescence of luciferases associated with nanoparticles may improve the applicability of bioluminescence for bioimaging and biosensing purposes.
\end{abstract}

Iseli L. Nantes-Cardoso

ilnantes@ufabc.edu.br; ilnantes@gmail.com

1 Universidade Federal do ABC (UFABC), Av. dos Estados, 5001, Bairro Bangu, Santo André, SP 09210-580, Brazil

2 Graduate School of Evolutive Genetics and Molecular Biology (UFSCar), São Carlos, SP, Brazil

3 Graduate School of Biotechnology and Environmental Monitoring (UFSCar), Sorocaba, SP, Brazil 


\section{Graphic abstract}

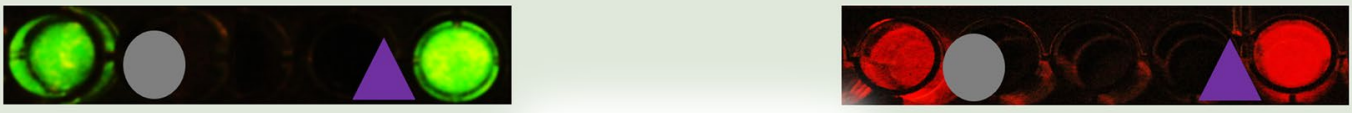

Enzyme Stability
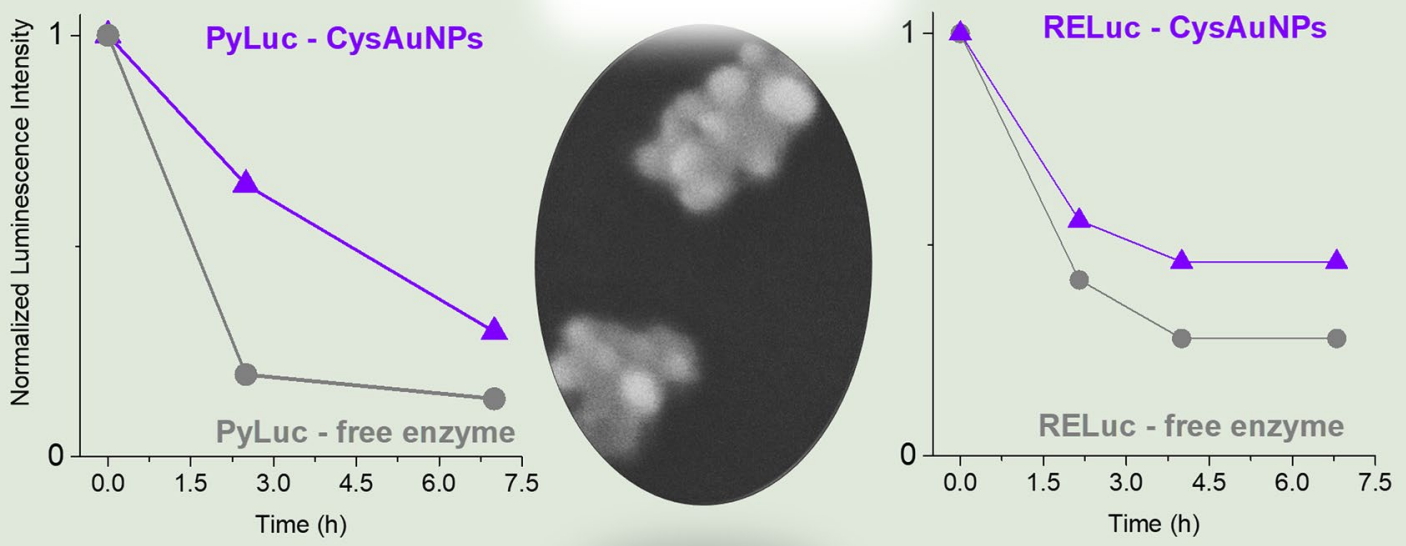

Keywords Gold nanoparticles $\cdot$ Magnetic nanoparticles $\cdot$ Luciferases $\cdot$ Bioluminescence $\cdot$ Dithiol-terminated polyethylene glycol $\cdot$ Nanotechnology

\section{Abbreviations}

AuNP Gold nanoparticles

Cys Cysteine

$\mathrm{PEG}(\mathrm{SH})_{2} \quad$ Dithiol-terminated polyethylene glycol

PyLuc Pyrearinus termitilluminans click beetle

RELuc Phrixothrix hirtus

\section{Introduction}

Hybrid systems formed by biomolecule-nanoparticle (NP) take advantage of the specificity and biocatalytic properties of biomolecules combined with the exclusive optical, electronic, and catalytic properties of nanostructured materials to develop materials with new strategic properties applicable for clean energy, environmental protection, smart clothes, diagnosis of new diseases and others [1-5]. Due to high catalytic efficiency, enzymes have gain preferential use for diverse industrial and therapeutic applications in which a catalyst is required. However, a drawback of enzyme application is the low stability and reusability, which can be overcome by enzyme immobilization on organic and inorganic nanostructures. The immobilization of enzymes in nanostructured materials have advantages such as: storage and operational stability, flexibility for the designing of bioreactors, high volume/size ratio that allow the loading of high mass of enzyme per mass of the nanocarrier. Also, specific advantages are provided by different nanostructures. High enzyme loading with very little mass transfer restrictions is an advantage of non-porous nanostructures, such as spherical gold and silver nanoparticles. Magnetic nanoparticles are highly appraised because of their high surface area, significant surface-to-volume ratio, low-cost production, biocompatibility and especially for providing easy enzyme recycling by magnetophoresis. Therefore, the immobilization of an enzyme with diverse applications can bring benefits to industry, health and technological areas [6].

Among a variety of enzymes, the luciferases are widely used for bioanalytical purposes, including their use as analytical reagents and enzymatic biosensors to detect analytes, cofactors, and enzymatic assays, [7]. Furthermore, the genes that code luciferases have an even wider range of applications, including their use as: markers to investigate gene expression in different organisms, including bacteria [8], plants $[9,10]$ and mammalian cells [11-13]; as proteome stress markers [14]; as indicators in cytotoxicity and cellbased assays [15]; in imaging of biological and pathological processes such as metastasis proliferation, viral and bacterial dissemination in animal models, including SARS-CoV-2 $[16,17]$, helping the pharmaceutical industry to develop HTS assays [12, 18-20], and in biosensors to detect environmental pollutants and disruptors [21], among others. 
Luciferases constitute a group of non-homologous enzymes responsible for bioluminescence, which catalyze the oxidation of chemically different luciferins by molecular oxygen to produce highly luminescent products, the oxyluciferins [22, 23]. The basic mechanism of luciferases involves the oxidation of the substrate luciferin with the formation of energy-rich peroxy intermediates whose spontaneous decomposition yields singlet excited oxyluciferin which decays emitting light with high efficiency [24, 25]. The generation of a singlet excited state product occurs in luciferase the active-site microenvironment, which are favorable for emissive decay rather than other photochemical and photophysical deactivating processes, making luciferases a special class of oxygenases specialized for light emission [22, 25-27].

In the case of beetles like fireflies, bioluminescence results from the oxidation of a benzothiazolic luciferin catalyzed by luciferases that require $\mathrm{Mg}^{2+}$-ATP as cofactor, to yield an excited oxyluciferin, $\mathrm{CO}_{2}$, AMP, and PPi (Scheme 1 in Supplemental Material) [24]. The light emission of beetle luciferase reactions using the same D-luciferin substrate exhibits distinct colors ranging from green to red $[27,28]$. The colors of beetle bioluminescence are basically determined by the luciferase active site microenvironment. Although the mechanisms of bioluminescence color determination by beetle luciferases has been debated over the past decades, currently it is accepted that physical-chemical properties of the active site microenvironment, such as its polarity, electrostatic and acid-base interactions with the excited oxyluciferin, especially with its 6-hydroxy group, and conformational effects, affects the energy of the excited state and therefore the emission spectra [28-31].

Despite the many analytical applications of beetle luciferases, the generally low enzyme stability and fast decay of luminescence reaction may limit their effective application. Different strategies have been used to stabilize the enzyme and changing the luminescence kinetics, including protein engineering and immobilization include their immobilization in gels $[32,33]$.

Immobilization of luciferases on metallic nanoparticles may offer a new strategy of stabilization of these enzymes for continuous bioluminescence monitoring of industrial processes, diagnosis and environmental purposes, and for delivery to specific tissues and organs during in vivo bioimaging of biological and pathological processes. The green emitting $P$. termitilluminans luciferase, due to its higher stability and more sustained luminescence [34] and higher quantum yield [35] has been already successfully used for bioimaging mammalian cells [35]. The luciferase of Phrixothrix railroad worm is the only one that naturally produces red emission [36]. Despite having been expressed and used for bioimaging in mammalian tissues [37], its application for mammalian tissue bioimaging is limited due to its instability and fast emission kinetics.
Recently improvements of this luciferase through engineering and combinatory chemistry resulted in a novel brighter and far-red emitting luciferase [38]. The association of these luciferases with nanoparticles is therefore a promising strategy to further increase their stability and sustain their luminescence for longer times for some bioanalytical and bioimaging applications.

Some recent technological applications of the luciferinluciferase system of fireflies include the use of nanostructures [39-41], including magnetic nanoparticles [20, 41-43]. However, the modulation of luciferase activity by the association with nanostructures is scarcely exploited [42-45]. Käkinen et al. reported a dose-dependent inhibition of firefly luciferase activity promoted by citrate-coated Ag nanoparticles (AgNPs). Enzyme inhibition was promoted by the reaction of $\mathrm{S}$ - and $\mathrm{N}$-groups with $\mathrm{Ag}^{+}$ions liberated by the NPs rather than by protein unfolding [44]. Abhijith et al. synthesized $\mathrm{Au}-\mathrm{Ag}$ NPs by the incorporation of $\mathrm{Ag}$ atoms during the steps of nanocrystal nucleation and growth. The Au-Ag colloids enhanced the bioluminescence of firefly and bacterial luciferases. The enhancement of bioluminescence could be applied to increase the sensitivity of luminescent-based assays that use firefly luciferase [45]. In another study, Ebrahimi et al. described the immobilization of $P$. pyralis luciferase expressed with $\mathrm{N}$-terminal His-tags on silanized $\mathrm{Ni}$ and $\mathrm{Cu}$-loaded magnetic nanoparticles. Immobilization decreased the affinity for ATP and increased the affinity for luciferin without changing the enzyme's thermal stability and longevity [43].

In the present study, the recombinant luciferases arising from two Brazilian bioluminescent beetles that elicit light emission of different colors, Pyrearinus termitilluminans larval click beetle (PyLuc: $538 \mathrm{~nm}$ ) and Phrixothrix hirtus railroad worm (RELuc: $623 \mathrm{~nm}$ ) were immobilized on PEG- and L-cysteine-coated AuNPs and magnetic Au/magnetite $\left(\mathrm{Fe}_{3} \mathrm{O}_{4}\right)$ NPs, and the effects on luminescence intensity, enzyme longevity and catalytic activity were evaluated. The study explores different configurations of AuNPs involving capping variation and magnetite hybridization to determine the best condition for luciferase functionalization to develop a nanotechnological platform. The bioluminescent enzyme conjugates can be applied for biosensing, immunologic assays, high-throughput screening, bioluminescence imaging, and other bioluminescence-based assays that could be benefited by enzyme longevity and recycling. The research also allowed the development of a method for the synthesis of AuNPs with interchangeable capping of thiol compounds, $\mathrm{PEG}(\mathrm{SH})_{2}$ and cysteine.

\section{Results and discussion}

Four types of AuNPs were synthesized with homobifunctional polyethylene glycol with thiol end groups $\left(\mathrm{PEG}(\mathrm{SH})_{2}\right)$ and characterized for immobilization of luciferases: 
PEG(SH) ${ }_{2} 8000$-coated AuNPs (PEG(SH) ${ }_{2}$ AuNPs), L-cysteine-coated AuNPs (CysAuNPs), the hybrid magnetic $\mathrm{NPs},\left(\mathrm{PEG}(\mathrm{SH})_{2} \mathrm{Au} / \mathrm{Fe}_{3} \mathrm{O}_{4} \mathrm{NPs}\right)$, and $\left(\mathrm{CysAu} / \mathrm{Fe}_{3} \mathrm{O}_{4} \mathrm{NPs}\right)$ for the association with luciferases.

\subsection{Chemical synthesis of AuNPs using PEG(SH) ${ }_{2} 8000$}

PEG is widely used to coat AuNPs after preparation by different methods, more usually those fabricated using sodium citrate and borohydride [46-48]. PEG terminated with thiol groups has also been used for in situ synthesis of AuNPs [49-51]. The capping of AuNPs with PEG confers stability and biocompatibility for a diverse range of applications. The present strategy was the use of $\mathrm{PEG}(\mathrm{SH})_{2} 8000$ to carry out an in situ synthesis of AuNPs using the thiol-terminated polymer as the reducing and stabilizing agents assisted by HEPES to accelerate the nucleation of AuNPs. The thiol groups of $\mathrm{PEG}(\mathrm{SH})_{2} 8000$ are efficient reducing agents, which, assisted by HEPES, promote the reduction of gold ions in the atomic form for the formation of AuNPs (Fig. 1). The use of $\mathrm{PEG}(\mathrm{SH})_{2} 8000$ as a reducing agent indicated that some of the thiol groups were oxidized and formed sulfonic acid $\left(\mathrm{SO}_{3} \mathrm{H}\right)$ derivatives as well as crosslinks of the polymer chains by disulfide bonds [47, 52] (Fig. 1).

The formation of AuNPs was characterized by the appearance of a surface plasmon resonance (SPR) band, DLS, FESEM-EDX images (Fig. 2A-C, respectively), and zeta potential (Table 1 in Supplemental Material). Figure 2A shows the spectra of PEG(SH) 28000 and AuNPs synthesized using the dithiol polymer as reducing agent and template. The AuNPs fabricated with $\mathrm{PEG}(\mathrm{SH})_{2} 8000$ exhibited a broad SPR band peaking at $532 \mathrm{~nm}$ and formed a stable violet-reddish colloidal suspension as shown in the snapshot inset of Fig. 2A. Figure 2B shows the DLS measurement that reveals a predominant population of nanostructures with a mean $R_{\mathrm{h}}$ (hydrodynamic radius) of $170 \mathrm{~nm}$. The $R_{\mathrm{h}}$, can be defined as the radius of a hypothetical hard sphere that diffuses at the same rate as particle that is under observation. Figure 2C-E shows the FESEM images of AuNPs produced with $\mathrm{PEG}(\mathrm{SH})_{2} 8000$. The supramolecular aggregates are not hard spheres and so, the determined $R_{\mathrm{h}}$ more closely reflects the apparent size adopted by the solvated, tumbling nanostructure and it is consistent with the size of aggregates that are shown by FESEM in Fig. 2C-E.

The FESEM images are consistent with the prediction that $\mathrm{PEG}(\mathrm{SH})_{2} 8000$ could crosslink and form supramolecular aggregates with AuNPs [47, 52]. Although FESEM images in Fig. 2C-E shows, in the polymer/NPs aggregates, individual nanoparticles with size around $15 \mathrm{~nm}$, a dispersion of the AuNPs was obtained replacing the polymer by L-cysteine as capping agent to more accurate determination of the size distribution of AuNPs. The suspension of AuNPs was submitted to three cycles of centrifugation and resuspension in a solution of L-cysteine $30 \mathrm{mmol} \mathrm{L}^{-1}$. Thiol groups of L-cysteine displace thiol groups of $\mathrm{PEG}(\mathrm{SH})_{2} 8000$ from AuNP surfaces and disassemble the supramolecular aggregates formed by the polymer and AuNPs. AuNPs
Fig. 1 Schematic representation of AuNP synthesis in situ using $\mathrm{PEG}(\mathrm{SH})_{2} 8000$ as reducing and stabilizing agents. In the first step of the synthesis, $\mathrm{Au}^{3+}$ is reduced to $\mathrm{Au}^{1+}$ assisted by HEPES. The oxidation of $\mathrm{PEG}(\mathrm{SH})_{2} 8000$ can produce sulfoxide and polymer crosslink. In the step 2, dismutation of $\mathrm{Au}^{+1}$ produces gold atoms that form gold nanoclusters associated to the partially oxidized polymer. In the third step AuNPs are formed by nanocrystal growing

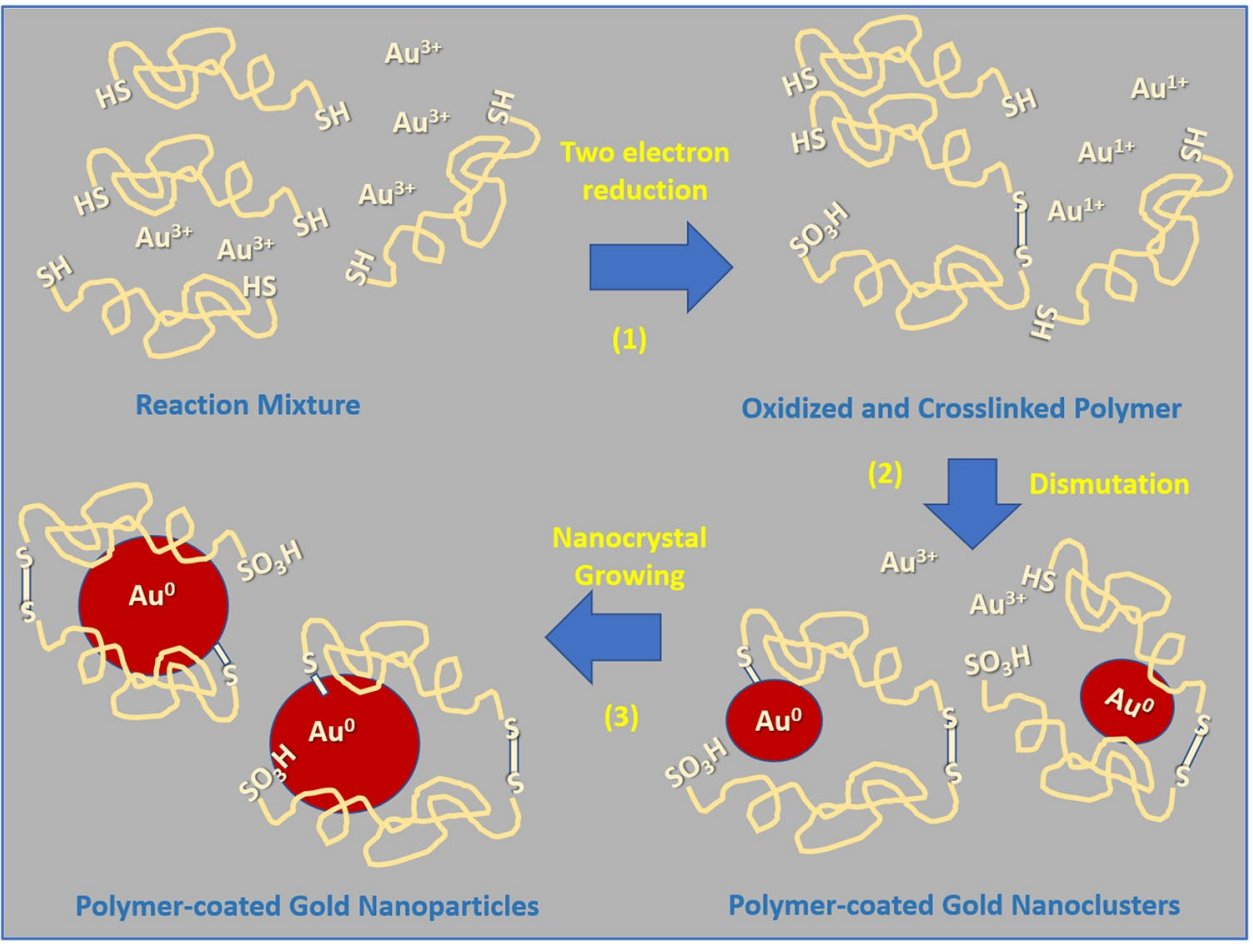




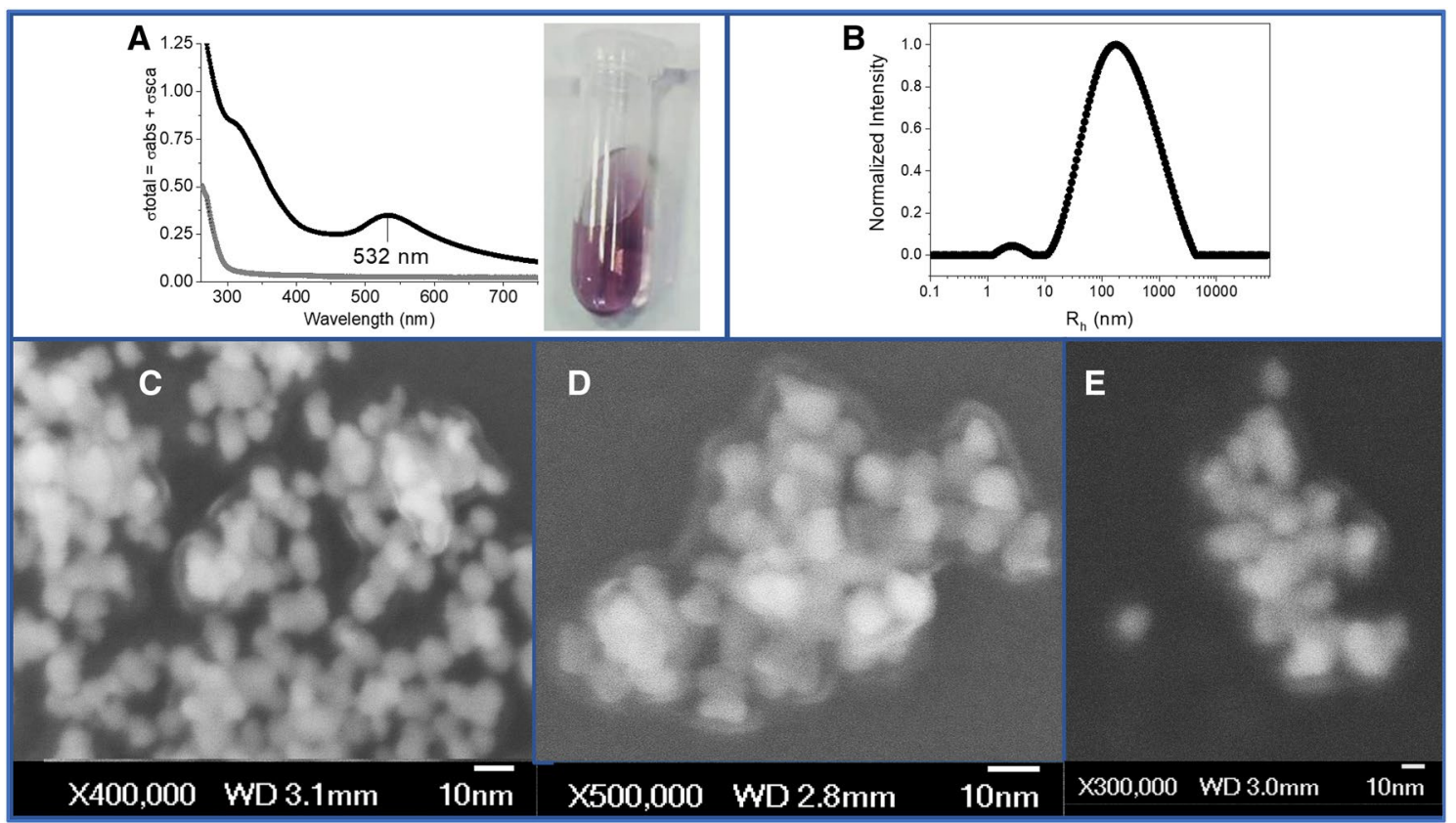

Fig. 2 Characterization of $\mathrm{PEG}(\mathrm{SH})_{2}$ AuNPs by UV-visible spectroscopy, FESEM and DLS. A SPR band of PEG(SH) ${ }_{2}$ AuNPs (black line) and $\mathrm{PEG}(\mathrm{SH})_{2}$ (gray line). The inset shows the snapshot of the colloidal suspension; B hydrodynamic radius distribution obtained

washed with L-cysteine solution were characterized by Zeta potential (Table 1 in Supplementary Material), FESEM (Fig. 3A), and XPS analysis (Fig. 3B, C). The replacement of $\mathrm{PEG}(\mathrm{SH})_{2} 8000$ by L-cysteine changed the zeta potential from $-2.1 \pm 1.1$ to $-16.7 \pm 0.5 \mathrm{mV}$ (Table 1 in Supplementary Material). The change in zeta potential of AuNPs after treatment with $\mathrm{L}$-cysteine is consistent with the replacement of PEG(SH) 28000 with the amino acid as the capping agent. The L-cysteine molecules bind to the AuNP surface by the sulfhydryl group of its lateral chain, leaving $\alpha$-carboxylic and $\alpha$-amino groups as the ionizable species contributing to the zeta potential. Above $\mathrm{pH} \sim 6$, which was the condition of the zeta potential measurements, the partial deprotonation of the $\alpha$-amino groups and almost total deprotonation of carboxylic groups contributed to the negative value of zeta potential [53]. It is important to consider that clustering of cysteines at the interface of AuNPs could make several amino groups to be in proximity leading to a significant lowering of the pKa value of the $\alpha$-amino groups of some molecules [54]. Other possibilities are the shielding of amino groups by reminiscent $\mathrm{PEG}(\mathrm{SH})_{2}$ molecules that remained associated with AuNPs or by interactions of the amino groups with AuNP surface decreasing the contribution of positively charged groups for the zeta potential.

The AuNPs capped by L-cysteine had the shape and size distribution determined by FESEM images (Fig. 3A) and were also characterized by XPS analysis of $\mathrm{Au} 4 \mathrm{f}$ and $\mathrm{O} 1 \mathrm{~s}$. by dynamic light scattering indicating a mean value of $170 \mathrm{~nm} ; \mathbf{C}-\mathbf{E}$ FESEM images of the PEG(SH) 2 AuNPs in which it is possible to distinguish the corona of $\mathrm{PEG}(\mathrm{SH})_{2} 8000$ probably crosslinked by disulfide bonds

The replacement of the polymer by L-cysteine coating provided good quality FESEM images that corroborated the formation of monodispersed AuNPs with a mean size of $15.6 \pm 0.2 \mathrm{~nm}$ (histogram in the inset of Fig. 3A). XPS spectrum of Au4f presented the typical sharp doublet peaks at $87.78 \pm 0.03 \mathrm{eV}$ and $84.08 \pm 0.03 \mathrm{eV}$ assigned respectively to $\mathrm{Au} 4 \mathrm{f} 7 / 2$ and $\mathrm{Au} 4 \mathrm{f} 5 / 2$ binding energies (BE) of nanoparticulated zero valent $\mathrm{Au}^{0}(87.7 \mathrm{eV}$ and $84.0 \mathrm{eV})$.[55]. The decomposition of the O1s XPS spectrum in Fig. 3C reveals BE peaks at $531.01 \pm 0.02,532.38 \pm 0.01$ and $534.6 \pm 0.1 \mathrm{eV}$ that can be assigned to oxygen of $\mathrm{C}=\mathrm{O}, \mathrm{C}-\mathrm{OH}$ and water, respectively [56]. The O1s XPS spectrum is consistent with the presence of L-cysteine on the AuNP surface due to the presence of carboxylic groups.

\subsection{Chemical synthesis of hybrid gold/magnetite nanoparticles using PEG(SH) ${ }_{2} 8000$}

Hybrid $\mathrm{Au} / \mathrm{Fe}_{3} \mathrm{O}_{4}$ NPs were synthesized using PEG(SH) 28000 . Nanoparticulated magnetite was first synthesized as previously described [57, 58]. $\mathrm{Fe}_{3} \mathrm{O}_{4} \mathrm{NPs}$ were dispersed in $\mathrm{PEG}(\mathrm{SH})_{2} 8000$ solution under stirring with the subsequent addition of $\mathrm{AuHCl}_{4}$. After the appearance of the SPR band, the free magnetite NPs were separated from the hybrid $\mathrm{Au} / \mathrm{Fe}_{3} \mathrm{O}_{4} \mathrm{NPs}$ by magnetophoresis. When a flask containing magnetite and $\mathrm{Au} / \mathrm{Fe}_{3} \mathrm{O}_{4} \mathrm{NPs}$ in suspension was approximated to a magnet, free magnetite was rapidly 


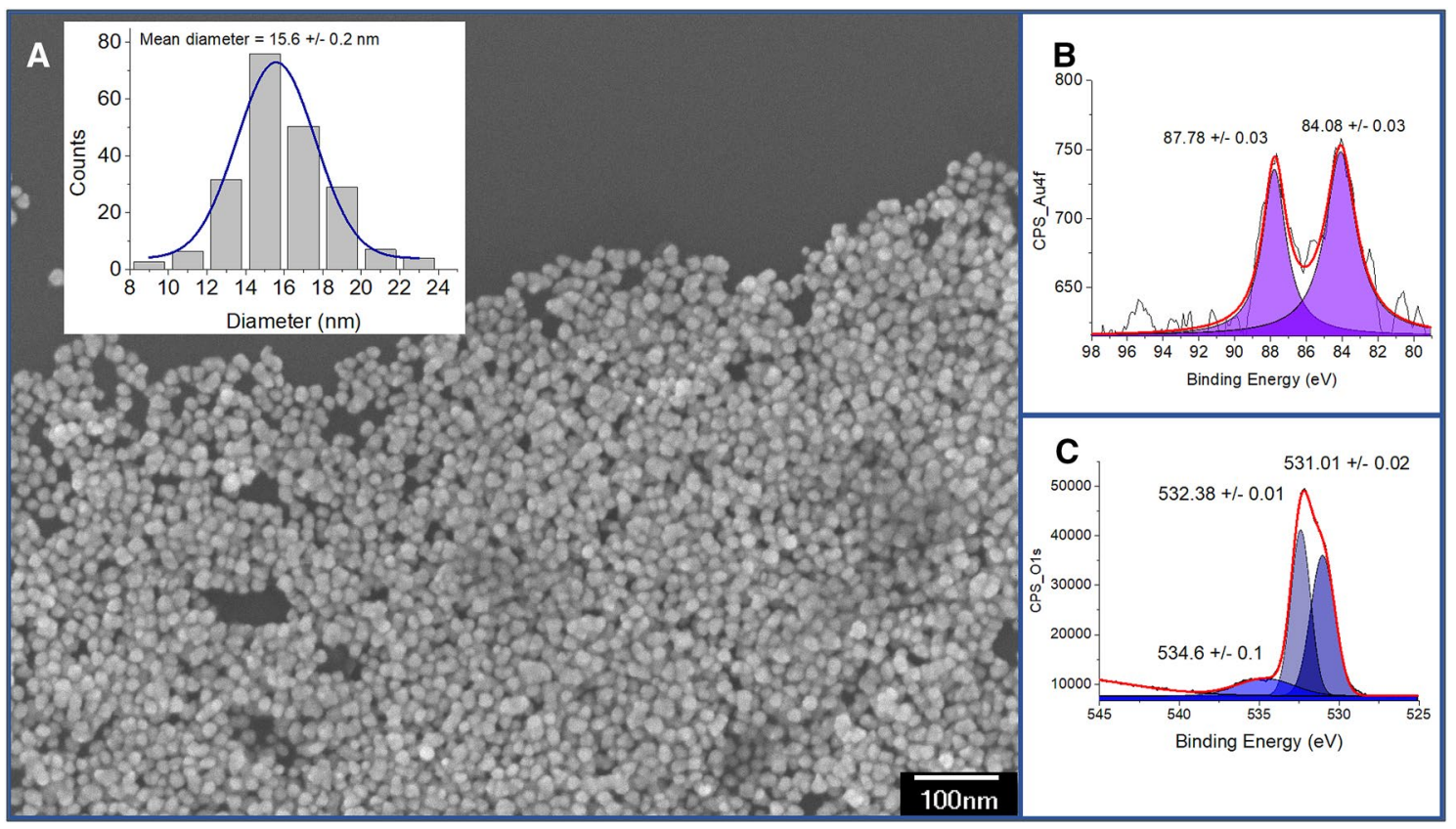

Fig. 3 Size, shape, and capping characterization of CysAuNPs. A FESEM images of the AuNPs with the inset showing the distribution of edge-to-edge distances obtained from FESEM images for
CysAuNPs. B, C Shows the respective XPS spectra of Au 4f, and 1Os XPS of CysAuNPs. The XPS band were deconvoluted by using the software Microcal Origin 9.0 multi peak fit tool attracted to the side of the flask wall that is sided by the magnet. While free magnetite was immobilized on the flask wall by magnet attraction, the suspension was collected using a pipette and transferred to another flask. The hybrid $\mathrm{Au} /$ $\mathrm{Fe}_{3} \mathrm{O}_{4}$ NPs were then slowly attracted by a magnet, and the non-magnetic material was collected using a pipette.

The $\mathrm{Au} / \mathrm{Fe}_{3} \mathrm{O}_{4}$ NPs were resuspended in water or in an L-cysteine solution and used for luciferase immobilization. The $\mathrm{Au} / \mathrm{Fe}_{3} \mathrm{O}_{4}$ NPs were characterized by FESEM (Fig. 4A), UV-visible spectrum (Fig. 4B), by FESEM EDX maps that corroborated co-localization of iron and gold elements in the NPs (Figure S1 in Supplemental material), and SQUID (Figure S2A and B in Supplemental material). Figure $4 \mathrm{~A}$ shows that the $\mathrm{Au} / \mathrm{Fe}_{3} \mathrm{O}_{4}$ NPs have a mean diameter of $17.3 \pm 0.6 \mathrm{~nm}$ and form aggregates by association with $\mathrm{PEG}(\mathrm{SH})_{2}$ The analysis of $\mathrm{PEG}(\mathrm{SH})_{2} \mathrm{Au} / \mathrm{Fe}_{3} \mathrm{O}_{4} \mathrm{NPs}$ by UV-visible spectroscopy showed an additional spectral contribution of magnetite associated with the AuNP SPR band that became $4 \mathrm{~nm}$ blue-shifted in comparison with PEG(SH) ${ }_{2}$ 8000AuNPs (green line). The inset shows a snapshot of the hybrid $\mathrm{PEG}(\mathrm{SH})_{2} \mathrm{Au} / \mathrm{Fe}_{3} \mathrm{O}_{4} \mathrm{NPs}$ suspension obtained by magnetophoresis.

\subsection{Fabrication and enzymatic activity of gold nanoparticle-luciferase hybrid systems}

Luciferases were immobilized on different NPs that were produced and their activities were measured. Immobilization was characterized by FTIR and FESEM. Figure 5A shows the FTIR spectra of free Py (green line) and RE (wine) luciferases, which show the contributions of typical protein amide I and amide II bands around 1650 and $1550 \mathrm{~cm}^{-1}$, respectively, from the bending of peptide $\mathrm{C}-\mathrm{O}$ stretching and $\mathrm{N}-\mathrm{H}$ bending in peptides (groups illustrated in panel D). The spectra also show bending modes of $\mathrm{CH}_{2}$ around $1460 \mathrm{~cm}^{-1}$, stretching of $\mathrm{C}-\mathrm{NH}_{2}$ around $1420 \mathrm{~cm}^{-1}$, and amide III band resulting from $\mathrm{C}-\mathrm{N}, \mathrm{C}-\mathrm{O}$, and $\mathrm{C}-\mathrm{C}-\mathrm{O}$ vibrations of the protein backbone and amino acid residues around $1330 \mathrm{~cm}^{-1}$ [59].

Figure 5B, C shows the FTIR spectral features of PEG(SH) 8000 AuNPs before (black line) and after the association with Py and RE luciferases (blue lines), respectively. In the spectral region of $1250-1800 \mathrm{~cm}^{-1}$, the FTIR spectrum of PEG(SH) 8000 AuNPs shows the contributions of $\mathrm{CH}_{2}$ scissoring at $1465 \mathrm{~cm}^{-1}, \mathrm{CH}_{2}$ wagging at $1353 \mathrm{~cm}^{-1}, \mathrm{C}-\mathrm{O}$ stretching at $1315 \mathrm{~cm}^{-1}$, and $\mathrm{CH}_{2}$ twisting at $1282 \mathrm{~cm}^{-1}$. The band at $1650 \mathrm{~cm}^{-1}$ is assigned to hydration water. The signal of water adsorbed on the AuNP surfaces is intensified by surface enhanced infrared absorption (SEIRA) effects [60]. The FTIR spectra of PEG(SH) 28000 AuNPs associated to luciferases (Fig. 5B, C, blue lines) clearly show the appearance of contributions assigned to amide I and amide III bands. In the FTIR spectrum of PEG(SH) 28000 AuNPs associated with luciferases, the contribution of amide II bands is missing, and shoulders around $1616 \mathrm{~cm}^{-1}$ and $1606 \mathrm{~cm}^{-1}$ seem to be associated 


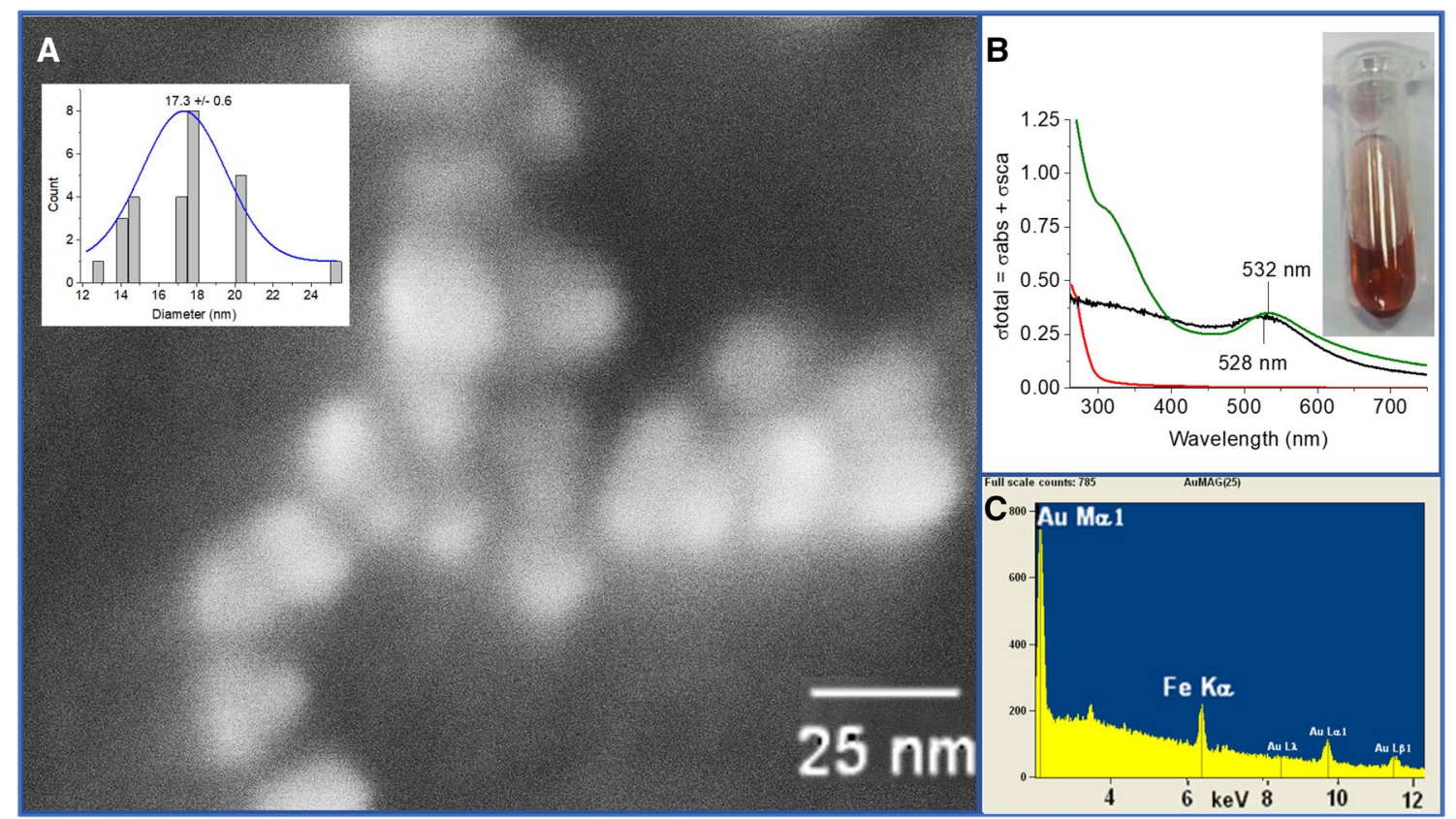

Fig. 4 Characterization of $\mathrm{PEG}(\mathrm{SH})_{2} \mathrm{Au} / \mathrm{Fe}_{3} \mathrm{O}_{4}$ NPs by size, shape, elemental composition and SPR band. A FESEM images of the NPs with the inset showing the distribution of edge-to-edge distances obtained from FESEM images for $\mathrm{PEG}(\mathrm{SH})_{2} \mathrm{Au} / \mathrm{Fe}_{3} \mathrm{O}_{4} \mathrm{NPs}$; B SPR band of PEG(SH) ${ }_{2} \mathrm{Au} / \mathrm{Fe}_{3} \mathrm{O}_{4}$ NPs (black line) overlapped with the SPR band of PEG(SH) $)_{2}$ AuNPs (green line) and PEG(SH)

with the band peaking at $1650 \mathrm{~cm}^{-1}$. This result is in good agreement with a similar phenomenon described for protein A conjugated with AuNPs [59]. The spectral change involving amide I and II bands of protein conjugated with AuNPs is presumed to be promoted by direct N-H moieties on the metal surface. In Fig. 5D, it is shown the PDB threedimensional structure of the homologous Luciola cruciata luciferase in the presence of DLSA (PDB code 2D1S) [61] from which the amino acid sequence 56AEY58 present in a $\alpha$-helix region was constructed using ACD/ChemSketch software to illustrate the type of vibrations responsible for amide I and amide II bands. Figure 5D also shows the groups of $\mathrm{PEG}(\mathrm{SH})_{2} 8000$ contributing to the vibrational spectra.

The sequence 56AEY58 region was aleatorily chosen only to illustrate peptide groups contributing for amide I, II and III bands. These groups in all the peptide chain extension contribute for these bands.

FESEM images of PEG(SH) 8000 AuNPs associated with PyLuc were obtained (Fig. 6A-C) and compared with an image of PEG(SH) 8000 AuNPs (Fig. 6D). The FESEM images of PEG(SH) 8000 AuNPs associated with Py (Fig. 6A-C) show a denser organic phase in the AuNP aggregates when compared with $\left(\mathrm{PEG}(\mathrm{SH})_{2} 8000\right.$ AuNPs image showed in $\mathrm{D}$ panel and others previously shown in Fig. 2C-E. (red line). The inset shows the snapshot of the colloidal suspension of $\mathrm{PEG}(\mathrm{SH})_{2} \mathrm{Au} / \mathrm{Fe}_{3} \mathrm{O}_{4} \mathrm{NPs}$; $\mathbf{C}$ representative EDX graphic with elemental contributions of AuM $\alpha 1$ and FeK $\alpha$. EDX maps showing colocalization of $\mathrm{Fe}$ and $\mathrm{Au}$, and graphics are available in Supplemental material: Figure S1A and B

The luminescence activities of Phrixothrix hirtus (RELuc) and Pyrearinus termitilluminans (PyLuc) luciferases were tested for both enzymes previously immobilized with $\mathrm{PEG}(\mathrm{SH})_{2}$, PEG(SH) 28000 AuNPs, CysAuNPs, $\mathrm{PEG}(\mathrm{SH})_{2} 8000 / \mathrm{Au} / \mathrm{Fe}_{3} \mathrm{O}_{4}$ NPs, and $\mathrm{Cys} / \mathrm{Au} / \mathrm{Fe}_{3} \mathrm{O}_{4}$ $\mathrm{NPs}$ and compared with the enzymes in buffered solution (Fig. 7A-D). A typical activity assay was performed in $100 \mu \mathrm{L}$ of total volume containing $85 \mu \mathrm{L}$ of $0.1 \mathrm{M}$ TRIS-HCl buffer ( $\mathrm{pH} 8.0$ ), $5 \mu \mathrm{L}$ of Phrixothrix hirtus luciferase (RELuc) at $0.056 \mu \mathrm{M}$ and Pyrearinus termitilluminans luciferase (PyLuc) at a concentration of $0.055 \mu \mathrm{M}$ associated with PEG or the AuNPs, $5 \mu \mathrm{L}$ of $\mathrm{LH}_{2}$ (luciferin) at a concentration of $10 \mathrm{mM}$ and $5 \mu \mathrm{L}$ of $\mathrm{Mg}^{2+}$ and ATP at concentrations of 4 and $2 \mathrm{mM}$, respectively.

PyLuc and RELuc in the free forms, and associated with $\mathrm{PEGSH}_{2}$ (black), $\mathrm{PEGSH}_{2} \mathrm{AuNPs}$ (navy), CysAuNPs (violet) $\mathrm{PEGSH}_{2} \mathrm{AuNPMag}$ (orange) and CysAuNPMag (dark yellow) were incubated with ATP and $\mathrm{Mg}^{2+}$ without LH2. After $2 \mathrm{~h}$ of incubation, aliquots of the incubated enzymes were deposited in the first row of wells of a 96-well microplate. Then, after addition of D-luciferin, the luminescence activity was read in the luminometer and imaged by a CCD camera (see snapshots as insets of Figure S3). After total times of 4, 6,9 and $50 \mathrm{~h}$ of enzyme incubation without $\mathrm{LH} 2$, the above procedures were repeated with the loading of successive 


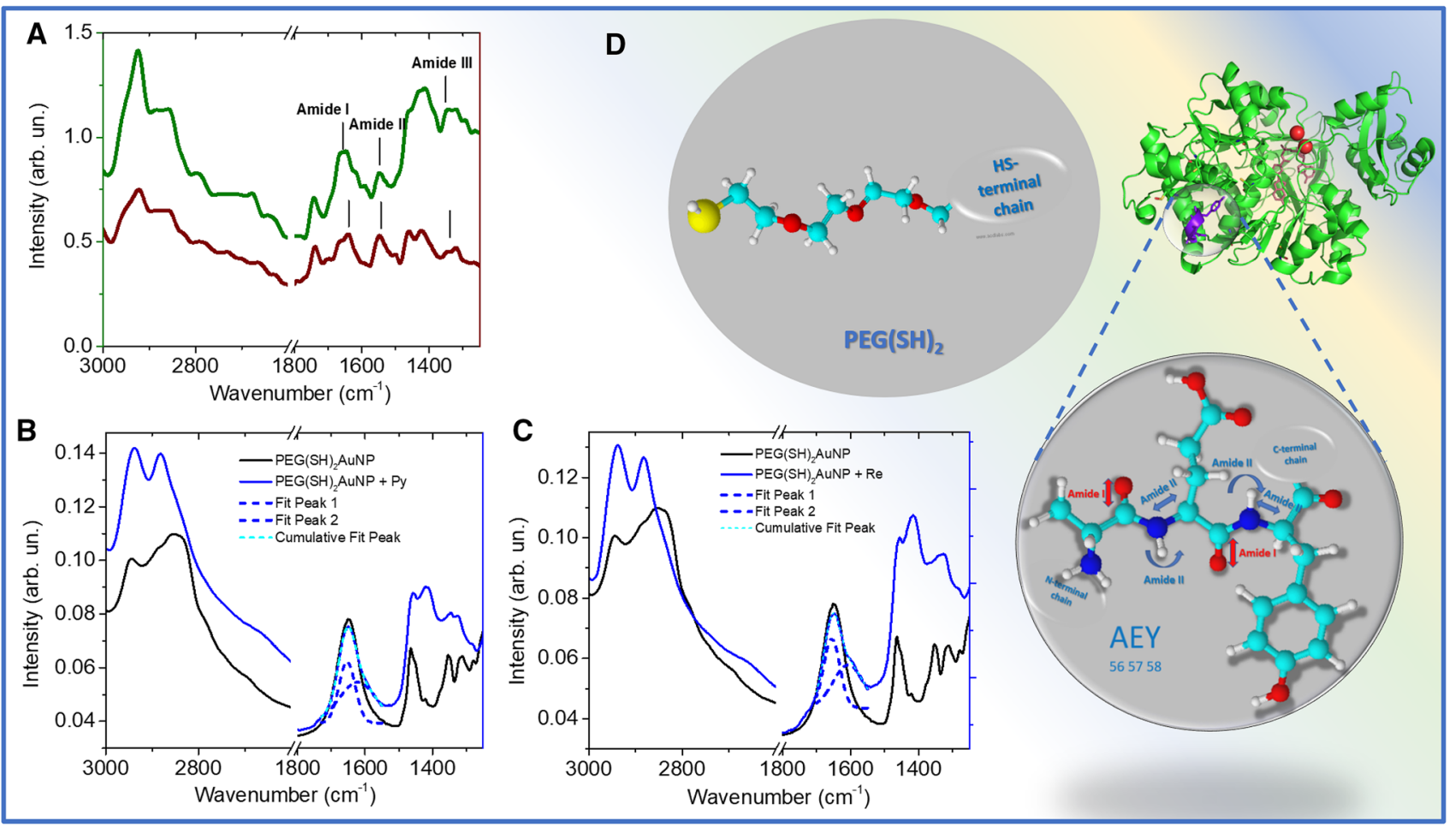

Fig. 5 Characterization of gold nanoparticle-luciferase hybrid system formation by FTIR. A FTIR spectra of free Py (green) and RE (wine) luciferases showing the contributions of typical protein amide I, amide II and amide III bands. B, C FTIR spectrum of PEG(SH)2AuNPs (black line) overlapped with the spectrum of AuNPs associated, respectively, with PyLuc and RELuc as blue lines. In these spectra, the region of $1600-1700 \mathrm{~cm}^{-1}$ was decomposed using the multi-peak fit tool of Origin software to show the double overlap contributions (cyan and blue dotted lines). D PDB threedimensional structure of Luciola cruciata luciferase in the presence of DLSA (PDB code 2D1S) with 56AEY58 amino-acid sequence that was aleatorily chosen to illustrate the vibrations responsible for amide I and amide II bands and a representation of $\mathrm{PEG}(\mathrm{SH})_{2}$ structure. The polymer and amino acid sequence structures were constructed with ACD/ChemSketch software

incubation periods (luminescence immediately after LH2 addition, Fig. 7A, C) and the luminescence kinetics (normalized luminescence decays of the enzyme incubated with $\mathrm{Mg}^{2+}$ and ATP for $2 \mathrm{~h}$, Fig. 7B, D). The measurements of immediate activity after different incubation times indicate the stability of the enzyme in the absence of the substrate. Figure 7B, D shows that the association of PyLuc and RELuc with $\mathrm{PEG}(\mathrm{SH})_{2}$ and functionalized AuNPs had an immediate effect on the luminescence intensity with different degrees of suppression. However, the enzymes' activity exhibited similar curves of activity decay in the different conditions. The association of PyLuc with PEG(SH) ${ }_{2} \mathrm{NPs}$ (blue triangles) and $\mathrm{PEG}(\mathrm{SH})_{2} \mathrm{NP} / \mathrm{Fe}_{3} \mathrm{O}_{4}$ (orange inverted triangles) promoted a significant decrease in luminescence after the addition of LH2 in all the steps of enzyme incubation. The association with $\mathrm{PEGSH}_{2}$, CysAuNPs and $\mathrm{CysAuFe}_{3} \mathrm{O}_{4} / \mathrm{NPs}$ were the conditions that better preserved the luminescence intensity relative to the free enzymes in solution. Cysteine is known to stabilize firefly luciferases, and its positive effect against luciferase inactivation suggests that oxidative damage and formation of disulfide bonds during incubation 


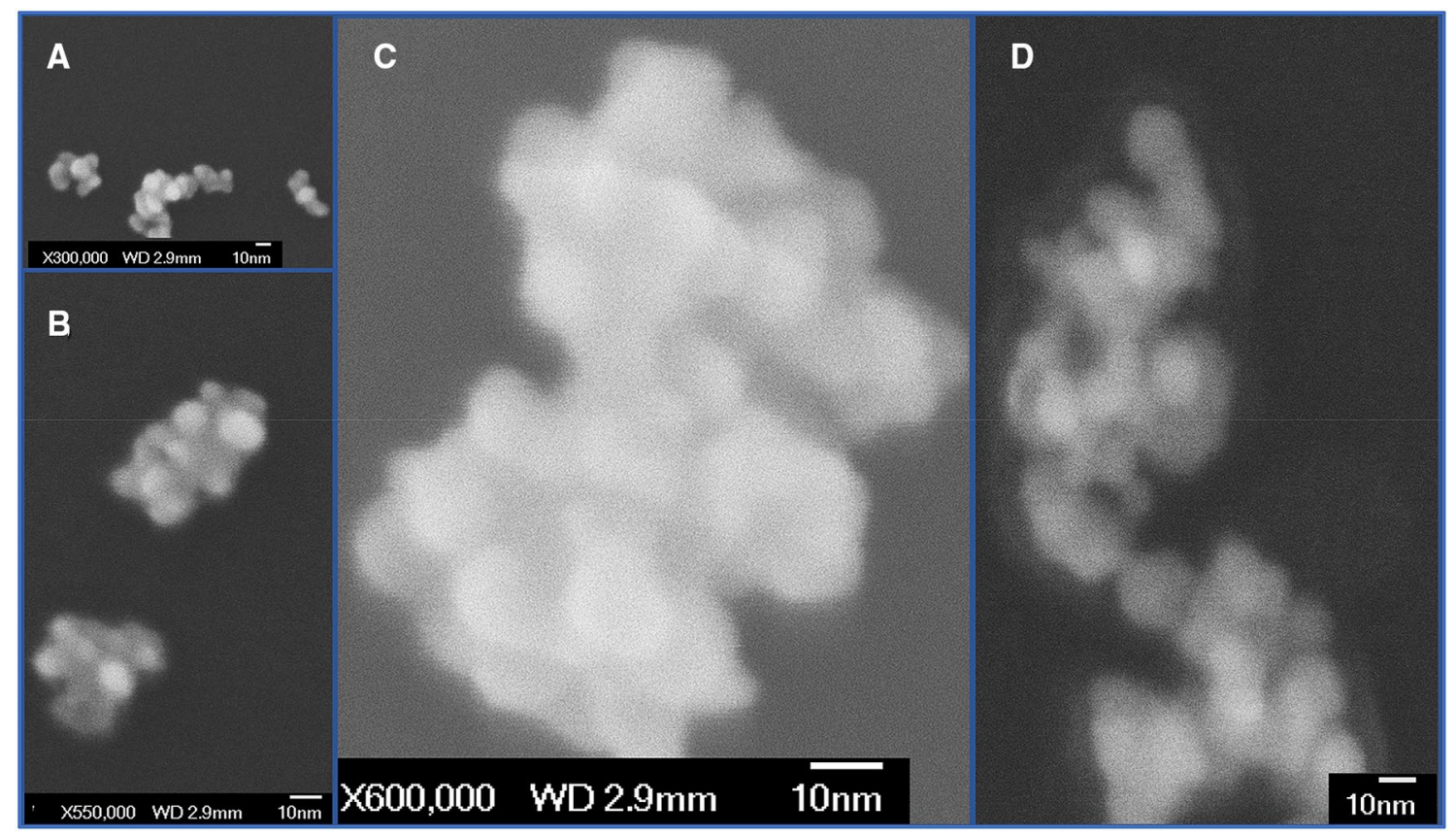

Fig. 6 A-D Are representative FESEM images of PEG(SH) $)_{2}$ AuNPs associated with PyLuc. A-C Show representative images of the samples containing PyLuc compared with the PEG(SH) $)_{2}$ AuNPs (D)

could contribute to the decrease in activity. However, other effects might also contribute to the luminescence decrease: conformational changes of luciferases bound on AuNPs evidenced by FTIR measurements (Fig. 5) and suppression of luminescence by the proximity of the luciferase active site to the metallic surface of NPs [63]. The association of fluorophores with metallic nanoparticles can enhance or decrease the fluorescence by Förster resonance energy transfer (FRET). Fluorescence enhancement occurred when the SPR band overlapped the fluorophore absorption band, and suppression was observed when the SPR band overlapped the fluorophore emission spectrum. Consistently, the highest fluorescence suppression was caused by $\mathrm{PEG}(\mathrm{SH})_{2} \mathrm{NPs}$ and $\mathrm{PEG}(\mathrm{SH})_{2} \mathrm{NP} / \mathrm{Fe}_{3} \mathrm{O}_{4}$, and the lowest quenching was caused by the enzyme association with $\mathrm{PEG}(\mathrm{SH})_{2}$, in which metallic NPs are absent. Time-dependent quenching promoted by metallic nanoparticles by means of a FRET mechanism can occur only when associated with progressive changes in the enzyme structure.

Similar results were obtained by the association of RELuc with PEG(SH $)_{2}$ and the diverse NPs, except that the time-dependent loss of activity in the absence of substrate (Fig. 7C) was faster for the enzyme associated with $\mathrm{PEG}(\mathrm{SH})_{2}$ than with CysAuNPs and $\mathrm{CysAuFe}_{3} \mathrm{O}_{4} / \mathrm{NPs}$. The effects of PEG(SH) $)_{2}$ and the different NPs on the enzymes after the addition of substrate (kinetics in Fig. 7B, D) are different from those observed for enzyme aging in the absence of substrate (Fig. 7A, C). The association with
CysAuNPs and $\mathrm{Cys} \mathrm{AuFe}_{3} \mathrm{O}_{4} / \mathrm{NPs}$ preserved the enzyme activity for a longer time ( $48 \mathrm{~h}$ ), whereas luminescence of free luciferases in solution exhibited fast decay of activity after $2 \mathrm{~h}$ of reaction. In the case of PyLuc, the decay of luminescence from the system containing free enzyme was faster than the luminescence decay of the enzyme associated with PEG(SH) $)_{2}, \mathrm{CysAuNPs}$, and $\mathrm{CysAuFe}_{3} \mathrm{O}_{4} /$ NPs. It is important to note that the luminescence decay is not promoted by substrate depletion because of the large excess of substrate used. The results obtained can be related to enzyme stability in the presence of substrate and the effect of products and side products on enzyme inhibition $[64,65]$. At relatively high substrate concentrations, the in vitro luminescence exhibits a flash pattern, which begins with an initial flash that quickly decays to a low basal level, as shown in Fig. 7B, D. The fast flash pattern decay of luminescence was suggested to be caused by an accumulation of inhibitory products, $\mathrm{OxyLH}_{2}$ $(K \mathrm{i}=0.50 \pm 0.03 \mathrm{mM})$, and especially dehydroluciferyladenylate (L-AMP) which is a strong competitive inhibitor $(K \mathrm{i}=3.8 \pm 0.7 \mathrm{nM}),[66]$ and also by conformational effects of the $\mathrm{C}$-terminal domain relative to the $\mathrm{N}$-terminal during the catalytic steps. Therefore, the inhibitory effects of products and side products can be apparently attenuated by the enzymes associated with $\mathrm{PEG}(\mathrm{SH})_{2}$, CysAuNPs, and $\mathrm{Cys} \mathrm{AuFe}_{3} \mathrm{O}_{4} / \mathrm{NPs}$, probably by affecting the mobility of the $\mathrm{N}^{\prime}$ and $\mathrm{C}^{\prime}$ subdomains, by impairing the binding of the inhibitors or both effects. 


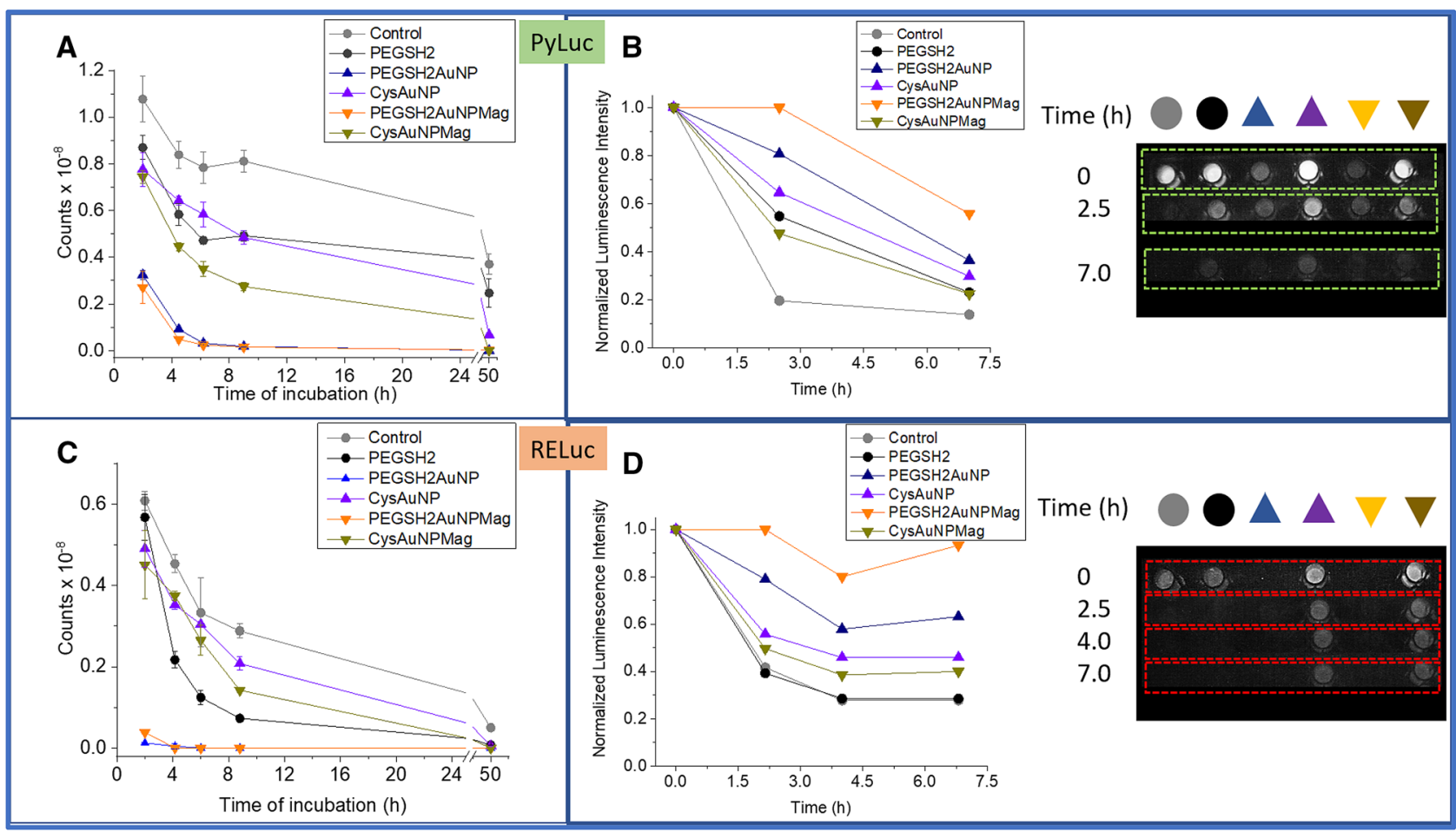

Fig. 7 Effect of the association with $\mathrm{PEG}(\mathrm{SH})_{2}$ and AuNPs on the stability and luminescence decays of luciferases. Graphics $\mathbf{A}$ and $\mathbf{B}$ refers to PyLuc results and $\mathbf{C}$ and $\mathbf{D}$ to RELuc results as indicated in the graphic legend in green and rose, respectively. A, C Effects of incubation time (aging) on the loss of PyLuc and RELuc activities, respectively, in different conditions: free in solution (grey), associated with $\mathrm{PEGSH}_{2}$ (black), $\mathrm{PEGSH}_{2}$ AuNPs (navy), CysAuNPs (violet) $\mathrm{PEGSH}_{2} \mathrm{AuNPMag}$ (orange) and CysAuNPMag (dark yellow).

B, D Effects of the association with $\mathrm{PEGSH}_{2}$ and different NPs on

\section{Conclusion}

$\mathrm{PEG}(\mathrm{SH})_{2}$ was used as a reducing and stabilizing agent for the synthesis of monodisperse AuNPs with a mean diameter of $\sim 15 \mathrm{~nm}$ and hybrid $\mathrm{Au} / \mathrm{Fe}_{3} \mathrm{O}_{4}$ NPs using previously synthesized nanoparticulated magnetite. The AuNPs synthesized using $\mathrm{PEG}(\mathrm{SH})_{2}$ formed aggregates stabilized by polymer capping on which PyLuc and RELuc were immobilized. The corona formed by $\mathrm{PEG}(\mathrm{SH})_{2}$ could be replaced by L-cysteine, followed by enzyme immobilization. The PyLuc nanoconjugates incubated for two hours, in the absence of substrate, showed different degrees of quenching when compared to the control. The smallest degrees of PyLuc bioluminescence quenching, immediately after substrate addition, were obtained with PEG(SH) $)_{2}(20 \%)$ and with CysAuNP and CysAuNPMag ( 30\%). AuNPs and AuNPMag functionalized with $\mathrm{PEG}(\mathrm{SH})_{2}$ promoted a quenching of $72 \%$ in the PyLuc bioluminescence. However, after $9 \mathrm{~h}$ of incubation without substrate, PyLuc conjugated with $\mathrm{PEG}(\mathrm{SH})_{2}$ exhibited $66 \%$ of bioluminescence quenching while CysAuNP and CysAuNPMag promoted $30 \%$ of the luminescence decay of PyLuc and RELuc, respectively, after LH2 addition and after $2 \mathrm{~h}$ of incubation with $\mathrm{Mg}^{2+}$ and ATP in the absence of substrate. The normalized decays were obtained from the well densitometry of white color in the snapshots (insets of $\mathbf{C}$ and $\mathbf{D}$, respectively), similarly to previously described by Yokomizo et al. [62]. The insets of $\mathbf{B}$ and $\mathbf{D}$ were composed by images of the first lines of wells as indicated in Figure S3 and S4 of Supplemental material

bioluminescence suppression. Considering the preservation of enzymatic activity, native PyLuc preserved only $20 \%$ of activity $2.5 \mathrm{~h}$ after substrate addition whereas conjugations with $\mathrm{PEG}(\mathrm{SH})_{2}$, CysAuNP, and CysAuNPMag preserved, respectively $55 \%, 64 \%$, and $48 \%$ of the initial activity. Important to note that the significant preservation of enzymatic activity observed for the conjugates with AuNPs and AuNPMag functionalized with $\mathrm{PEG}(\mathrm{SH})_{2}$ are not important due to the high degree of bioluminescence quenching promoted by these nanostructures. For RELuc, a high degree of suppression was also observed after association with AuNPs and AuNPMag functionalized with PEG(SH) RELuc conjugation with $\mathrm{PEG}(\mathrm{SH})_{2}$ promoted the lowest degree of quenching $(7 \%)$ after $2 \mathrm{~h}$ of incubation followed by CysAuNP (17\%) and CysAuNPMag (25\%). However, for RELuc, conjugation with PEG(SH $)_{2}$ and CysAuNPMag were inefficient in protecting the enzyme during incubation in the absence of substrate. In these conjugates the activity decreased, respectively, $75 \%$ and $55 \%$, compared to the control after $9 \mathrm{~h}$ of incubation without substrate. On the other hand, RELuc associated with CysAuNP and incubated 
for $9 \mathrm{~h}$ in the absence of substrate, showed a loss of $28 \%$ of the initial activity compared to the control. For RELuc, conjugations with CysAuNP and CysAuNPMag were the most efficient in preserving the enzymatic activity, which remained at about $50 \% 2.5 \mathrm{~h}$ after the addition of the substrate. The association with CysAuNPs resulted in a better combination of persistence of luminescence activity with a low degree of luminescence quenching, probably because of isolated or combinatory effects of L-cysteine antioxidant action, impairment of inhibitory effects by products and side products access to the enzymes, and controlled access of the substrate to the enzyme active site. The elucidation of these mechanisms requires additional research in our laboratories. The higher enzymatic stability and more sustained luminescence of luciferase associated with nanoparticles may increase the effective applicability of bioluminescence for different bioanalytical purposes, including bioimaging, biosensors and immunoassays.

\section{Materials and methods}

All solutions were prepared with reagents of analytical grade, used as acquired without any further purification, and ultrapure water (Milli-Q, $18.2 \mathrm{~m} \Omega \mathrm{cm}^{-1}$ ). Hydrogen tetrachloroaurate $\left(\mathrm{HAuCl}_{4}\right)$, chloride acid, sodium hydroxide, mono-and dibasic sodium phosphate, HEPES buffer, L-cysteine, and homobifunctional polyethylene glycol with thiol end groups (PEG dithiol) were supplied by SigmaAldrich (St. Louis, Missouri, EUA). Ferric chloride (98\%, anhydrous $\mathrm{FeCl}_{3}$ ), ferrous chloride tetrahydrate (98\%, $\left.\mathrm{FeCl}_{2} \cdot 4 \mathrm{H}_{2} \mathrm{O}\right)$, and ammonium hydroxide $\left(98 \%, \mathrm{NH}_{4} \mathrm{OH}\right)$ were purchased from Vetec Química Fina (Rio de Janeiro, RJ, Brazil). The aqueous solutions and suspensions were prepared with deionized water (mixed bed of ion exchange, Millipore $\left.{ }^{\circledR}\right)$, and the $\mathrm{pH}$ was measured using a combined glass electrode (Orion Glass pH SURE-FLOW ${ }^{\mathrm{TM}}$ ). The reference electrode (ROSS ${ }^{\mathrm{TM}}$, model 8102) was filled with Orion Filling Solutions (ROSS ${ }^{\mathrm{TM}}$ ). The $\mathrm{pH}$ meter was calibrated using METREPAK pHydrion standard buffer solutions (Brooklyn, NY, USA). The glass vials used for the synthesis of gold nanoparticles were cleaned with aqua regia solution $\left(1: 3-\mathrm{HNO}_{3} / \mathrm{HCl}\right)$ to avoid contamination with potential artificial nucleation sites.

Gold nanoparticle gold nanoparticles were synthesized at room temperature in $30 \mathrm{mM}$ HEPES, and sodium phosphate buffered solutions of $4 \mathrm{mM}$ PEG dithiol 8000 (PEG(SH) $8000)$ at $\mathrm{pH} 10$ according to a method using a reagent ratio of $5 / 1$ thiol/ $\mathrm{HAuCl}_{4}$ and HEPES as the reducing agent for gold nanoparticle nucleation. Hydrogen tetrachloroaurate $\left(\mathrm{HAuCl}_{4}\right)$ was added to $\mathrm{PEG}(\mathrm{SH})_{2} 8000$ under stirring at a final concentration of $0.4 \mathrm{mM}$. The reddish-violet color and appearance of the surface plasmon resonance band at $532 \mathrm{~nm}$ in the UV-vis spectra of the reaction mixture confirmed the formation of AuNPs. The replacement of PEG(SH) $)_{2} 8000$ by L-cysteine as the capping agent of AuNPs was done by successive, at least three, washing of the AuNPs in $1.5 \mathrm{mM}$ of L-cysteine solution. The colloidal suspension was centrifuged at 14,000 rpm for AuNP sedimentation, the supernatant was removed and replaced with an equal volume of L-cysteine solution, and the procedure was repeated at least three times. After washing with L-cysteine solution, the colloidal suspension exhibited a red color, and the turbidity decreased. $\mathrm{Au} / \mathrm{Fe}_{3} \mathrm{O}_{4}$ NPs were synthesized by the addition of previously fabricated and characterized nanoparticulated magnetite $\left(\mathrm{Fe}_{3} \mathrm{O}_{4}\right)$ [58] in $4 \mathrm{mM} \mathrm{PEG}(\mathrm{SH})_{2} 8000$ at $\mathrm{pH} 10$, followed by the addition of $\mathrm{HAuCl}_{4}$ stock solution under stirring. Magnetite synthesis was carried out according to Barreto et al. [58]. Briefly, $0.023 \mathrm{M}$ ferric chloride solution was mixed with $0.027 \mathrm{M}$ ferrous chloride solution. The mixed solution was stirred under a nitrogen atmosphere and kept at room temperature to maintain a molar $\mathrm{Fe}^{2+} / \mathrm{Fe}^{3+}$ ratio of $1 / 2$. In sequence, $33.5 \mathrm{~mL}$ of a concentrated solution of $\mathrm{NH}_{4} \mathrm{OH}(27 \%)$ was added ( $\mathrm{pH}$ in the range of -10 to 11.8 ), leading to the immediate formation of a black precipitate. The mixture was stirred at $2000 \mathrm{rpm}$ for $30 \mathrm{~min}$ under magnetic stirring. The product was decanted, washed three times, and dried at $40{ }^{\circ} \mathrm{C}$ for several hours.

UV/vis absorption spectroscopy spectra were recorded using a Thermo Fisher Spectrophotometer (Evolution 220), using a $1 \mathrm{~cm}$ quartz cuvette, made at room temperature.

Fourier transform infrared spectroscopy infrared spectroscopy was carried out in ATR mode (attenuated total reflection) in a Varian AIM- 8800 coupled to the microscope. The suspensions of nanoparticles were dropped on the surface of the diamond crystal and slowly dried in the presence of silica particles in proximity to the crystal.

FESEM images and energy dispersive $X$-ray analysis high-magnification images of the nanoparticles were obtained by field emission scanning electron microscopy (FESEM; JEOL model JMS-6701F) with an energy-dispersive $\mathrm{X}$-ray spectrometer attached for chemical characterization (EDX, Thermo Scientific, model NORAN SystemNano Trace detector). A small drop of the sample to be analyzed was plotted on a piece of a doped silicon substrate. The sample was dried for several hours prior to image acquisition. The acceleration voltage used for the FESEM images was $5 \mathrm{kV}$, and for the EDX analysis was $10 \mathrm{kV}$.

$X$-ray photoelectron spectroscopy (XPS) analysis was performed using K-alpha (Thermo Fisher Scientific).

Zeta potential and dynamic light scattering the zeta potential $(\zeta)$ analysis of the samples was performed using a Zetasizer Nano ZS (Malvern Instruments). The potential values were determined as the average of the electrophoretic mobility values using the Smoluchowski equation [67]. The measurements were carried out using an ALV/ 
CGS-3 compact goniometer system consisting of a $22 \mathrm{~mW}$ $\mathrm{HeNe}$ linearly polarized laser operating at a wavelength of $633 \mathrm{~nm}$, an ALV 7004 digital correlator, and a pair of avalanche photodiodes operating in pseudo-cross-correlation mode. The colloidal suspensions were placed in $10 \mathrm{~mm}$ diameter glass cells and maintained at a constant temperature of $25{ }^{\circ} \mathrm{C}$. The functions of autocorrelation were obtained from three independent runs with a counting time of $60 \mathrm{~s}$. The data were collected and treated using ALV Correlator Control software.

Luciferase expression and purification plasmid pCold (Takara, Japan) carrying the cDNAs for $P$. hirtus railroadworm red emitting luciferase (RE) and Pyrearinus termitilluminans (Py) click beetle green emitting luciferase were used to transform $E$. coli BL21. The transformed bacteria were grown in $100 \mathrm{~mL} \mathrm{LB}$ medium until $\mathrm{OD}_{600}=0.4$, and then induced for protein expression with $0.4 \mathrm{mM}$ IPTG at $18{ }^{\circ} \mathrm{C}$ overnight. The induced bacteria were centrifuged at $2500 \times g$ for $15 \mathrm{~min}$ at $4{ }^{\circ} \mathrm{C}$, and the resulting bacterial pellet was used for luciferase extraction. The bacterial pellet was extracted in $50 \mathrm{mM}$ sodium Phosphate buffer, $300 \mathrm{mM}$ $\mathrm{NaCl}, 10 \mathrm{mM}$ imidazole and protease inhibitor cocktail (Roche), $\mathrm{pH} 7.0$, lysed by ultrasonication and centrifuged at $15,000 \times g$ for $15 \mathrm{~min}$ at $4{ }^{\circ} \mathrm{C}$. Posteriorly, luciferase was purified by Nickel-agarose affinity chromatography. The crude extracts were then incubated with Nickel-agarose, washed with $50 \mathrm{mM}$ sodium Phosphate buffer, $300 \mathrm{mM}$ $\mathrm{NaCl}, 20 \mathrm{mM}$ imidazole, $\mathrm{pH} 7.0$ and finally the luciferases were eluted with Phosphate buffer, $300 \mathrm{mM} \mathrm{NaCl}, 250 \mathrm{mM}$ imidazole, $\mathrm{pH}$ 7.0. Protein concentration was estimated by Bradford method. The stock solution concentration to make the nanoparticle Synthesis were $\sim 0.23 \mathrm{mg} / \mathrm{mL}$ or $3.77 \mu \mathrm{M}$ for both luciferases.

Luminescence assay the luminescence intensity was measured using an AB2200 luminometer (ATTO, Tokyo) in counts per second (cps). Bioluminescence was also imaged using a light capture II CCD camera (ATTO, Tokyo, Japan). The sample was obtained by mixing $85 \mu \mathrm{L} 0.10 \mathrm{M}$ Tris- $\mathrm{HCl} \mathrm{pH} 8.0 ; 5 \mu \mathrm{L}$ of purified enzyme, $5 \mu \mathrm{L}$ of $40 \mathrm{mM}$ ATP, $80 \mathrm{mM} \mathrm{MgSO}_{4}$ and $5 \mu \mathrm{L}$ of $10 \mathrm{mM}$ D-luciferin.

Bioluminescence spectra the in vitro bioluminescence spectra were measured using a $\mathrm{AB}-1850$ Lumi FI Spectro Capture spectroluminometer (ATTO, Tokyo), by mixing $85 \mu \mathrm{L} 0.10 \mathrm{M}$ Tris- $\mathrm{HCl} \mathrm{pH} 8.0 ; 5 \mu \mathrm{L}$ of purified enzyme, $5 \mu \mathrm{L}$ of $40 \mathrm{mM}$ ATP, $80 \mathrm{mM} \mathrm{MgSO}_{4}$ and $5 \mu \mathrm{L}$ of $10 \mathrm{mM}$ D-luciferin.

Supplementary Information The online version contains supplementary material available at https://doi.org/10.1007/s43630-021-00111-0.

Acknowledgements The authors are grateful to FAPESP 2010/054268, 2015/17688-0; 2017/02317-2, CNPq 401867/2016-1, 401827/20161, Biochemistry and Biotechnological Strategic Research Core (NBB), and David da Mata Lopes for their technical support and the Multiuser Central Facilities (UFABC) for their experimental support.

Author contributions The manuscript was written through the contributions of all the authors. All authors approved the final version of the manuscript.

Funding The research of the manuscript was supported by FAPESP 2010/05426-8, 2015/17688-0; 2017/02317-2, CNPq 401867/2016-1; 401827/2016-1.

Data availability The datasets generated during and/or analyzed during the current study are available from the corresponding author on reasonable request.

\section{Declarations}

Conflict of interest The authors declare no competing interests.

Ethical approval Not applicable.

\section{References}

1. Palomo, J. M. (2019). Nanobiohybrids: A new concept for metal nanoparticles synthesis. Chemical Communications, 55(65), 9583-9589. https://doi.org/10.1039/c9cc04944d

2. Willner, I., Basnar, B., \& Willner, B. (2007). Nanoparticle-enzyme hybrid systems for nanobiotechnology. FEBS Journal, 274(2), 302-309. https://doi.org/10.1111/j.1742-4658.2006.05602.x

3. Pereira, A. R., Iost, R. M., Martins, M. V. A., Yokomizo, C. H., da Silva, W. C., Nantes, I. L., \& Crespilho, F. N. (2011). Molecular interactions and structure of a supramolecular arrangement of glucose oxidase and palladium nanoparticles. Physical Chemistry Chemical Physics. https://doi.org/10.1039/c1cp20432g

4. Dias, C. F., Araújo-Chaves, J. C., Mugnol, K. C., Trindade, F. J., Alves, O. L., Caires, A. C., Brochsztain, S., Crespilho, F. N., Matos, J. R., Nascimento, O. R., \& Nantes, I. L. (2012). Photoinduced electron transfer in supramolecular materials of titania nanostructures and cytochrome c. RSC Advances. https://doi.org/ $10.1039 / \mathrm{c} 2 \mathrm{ra} 20996 \mathrm{a}$

5. Kopac, T. (2021). Protein corona, understanding the nanoparticle-protein interactions and future perspectives: A critical review. International Journal of Biological Macromolecules. https://doi. org/10.1016/j.ijbiomac.2020.12.108

6. Schmieg, B., Nguyen, M., \& Franzreb, M. (2020). Simulative minimization of mass transfer limitations within hydrogel-based 3D-printed enzyme carriers. Frontiers in Bioengineering and Biotechnology, 8, 365. https://doi.org/10.3389/fbioe.2020.00365

7. Pelentir, G. F., Bevilaqua, V. R., \& Viviani, V. R. (2019). A highly efficient, thermostable and cadmium selective firefly luciferase suitable for ratiometric metal and $\mathrm{pH}$ biosensing and for sensitive ATP assays. Photochemical and Photobiological Sciences, 18(8), 2061-2070. https://doi.org/10.1039/c9pp00174c

8. Shaw, J. J., \& Kado, C. I. (1986). Development of a vibrio bioluminescence gene-set to monitor phytopathogenic bacteria during the ongoing disease process in a non-disruptive manner. Bio/ Technology, 4(6), 560-564. https://doi.org/10.1038/nbt0686-560

9. Millar, A. J., Short, S. R., Hiratsuka, K., Chua, N. H., \& Kay, S. A. (1992). Firefly luciferase as a reporter of regulated gene expression in higher plants. Plant Molecular Biology Reporter, 10(4), 324-337. https://doi.org/10.1007/BF02668909 
10. Villao, L., Sánchez, E., Romero, C., Galarza, L., Flores, J., \& Santos-Ordóñez, E. (2019). Activity characterization of the plantain promoter from the heavy metal-associated isoprenylated plant gene (MabHIPP) using the luciferase reporter gene. Plant Gene, 19(June), 4-8. https://doi.org/10.1016/j. plgene.2019.100187

11. Hikita, T., Miyata, M., Watanabe, R., \& Oneyama, C. (2018). Sensitive and rapid quantification of exosomes by fusing luciferase to exosome marker proteins. Scientific Reports, 8(1), 1-14. https://doi.org/10.1038/s41598-018-32535-7

12. Dai, Z. T., Yao, A., Xiang, Y., Li, J. P., Guo, W., Zhang, H. M., Huang, F., Li, H. H., Zhang, Z. J., Li, H., \& Liao, X. H. (2019). MKL-1 regulates the stem cell marker. CD44 in breast cancer cells. E3S Web of Conferences, 78, 1-5. https://doi.org/10.1051/ e3sconf/20197801002

13. Lorenz, W. W. (1996). Expression of the Renilla reniformis luciferase gene in mammalian cells. Journal of Bioluminescence and Chemiluminescence, 11(1), 31-37. https://doi.org/10.1002/ (sici)1099-1271(199601)11:1\%3c31::aid-bio398\%3e3.3.co;2-d

14. Gupta, R., Kasturi, P., Bracher, A., Loew, C., Zheng, M., Villella, A., Garza, D., Hartl, F. U., \& Raychaudhuri, S. (2011). Firefly luciferase mutants as sensors of proteome stress. Nature Methods, 8(10), 879-884. https://doi.org/10.1038/nmeth.1697

15. Matta, H., Gopalakrishnan, R., Choi, S., Prakash, R., Natarajan, V., Prins, R., Gong, S., Chitnis, S. D., Kahn, M., Han, X., \& Chaudhary, V. (2018). Development and characterization of a novel luciferase based cytotoxicity assay. Scientific Reports, 8(1), 1-14. https://doi.org/10.1038/s41598-017-18606-1

16. Rodriguez, J. F., Rodriguez, D., Rodriguez, J. R., McGowan, E. B., \& Esteban, M. (1988). Expression of the firefly luciferase gene in vaccinia virus: A highly sensitive gene marker to follow virus dissemination in tissues of infected animals. Proceedings of the National Academy of Sciences of the United States of America, 85(5), 1667-1671. https://doi.org/10.1073/pnas.85.5. 1667

17. Yao, Z., Drecun, L., Aboualizadeh, F., Kim, S. J., Li, Z., Wood, H., Valcourt, E. J., Manguiat, K., Plenderleith, S., Yip, L., \& Li, X. (2021). A homogeneous split-luciferase assay for rapid and sensitive detection of anti-SARS CoV-2 antibodies. Nature Communications, 12(1), 1806. https://doi.org/10.1038/s41467-021-22102-6

18. Hall, M. P., Woodroofe, C. C., Wood, M. G., Que, I., van't Root, M., Ridwan, Y., Shi, C., Kirkland, T. A., Encell, L. P., Wood, K. V., \& Löwik, C. (2018). Click beetle luciferase mutant and near infrared naphthyl-luciferins for improved bioluminescence imaging. Nature Communications, 9(1), 1-12. https://doi.org/10.1038/ s41467-017-02542-9

19. Bevilaqua, V. R., Matsuhashi, T., Oliveira, G., Oliveira, P. S. L., Hirano, T., \& Viviani, V. R. (2019). Phrixotrix luciferase and 6 -aminoluciferins reveal a larger luciferin phenolate binding site and provide novel far-red combinations for bioimaging purposes. Scientific Reports, 9(1), 1-17. https://doi.org/10.1038/ s41598-019-44534-3

20. Vasquez, E. S., Feugang, J. M., Willard, S. T., Ryan, P. L., \& Walters, K. B. (2016). Bioluminescent magnetic nanoparticles as potential imaging agents for mammalian spermatozoa. Journal of Nanobiotechnology, 14(1), 1-9. https://doi.org/10.1186/ s12951-016-0168-y

21. Ripp, S., Nivens, D. E., Ahn, Y., Werner, C., Jarrell, J., Easter, J. P., Cox, C. D., Burlage, R. S., \& Sayler, G. S. (2000). Controlled field release of a bioluminescent genetically engineered microorganism for bioremediation process monitoring and control. Environmental Science and Technology, 34(5), 846-853. https://doi. org/10.1021/es9908319

22. Kaskova, Z. M., Tsarkova, A. S., \& Yampolsky, I. V. (2016). 1001 lights: Luciferins, luciferases, their mechanisms of action and applications in chemical analysis, biology and medicine.
Chemical Society Reviews, 45(21), 6048-6077. https://doi.org/ $10.1039 / \mathrm{c} 6 \mathrm{cs} 00296 \mathrm{j}$

23. Fleiss, A., \& Sarkisyan, K. S. (2019). A brief review of bioluminescent systems (2019). Current Genetics, 65(4), 877-882. https:// doi.org/10.1007/s00294-019-00951-5

24. Viviani, V. R. (2002). The origin, diversity, and structure function relationships of insect luciferases. Cellular and Molecular Life Sciences, 59(11), 1833-1850. https://doi.org/10.1007/PL000 12509

25. Vacher, M., Fdez. Galván, I., Ding, B. W., Schramm, S., BerraudPache, R., Naumov, P., Ferre, N., Liu, Y. J., Navizet, I., RocaSanjuan, D., Baader, W. J., \& Lindh, R. (2018). Chemi- and bioluminescence of cyclic peroxides. Chemical Reviews, 118(15), 6927-6974. https://doi.org/10.1021/acs.chemrev.7b00649

26. Hastings, J. W. (1996). Chemistries and colors of bioluminescent reactions: A review. Gene, 173(1), 5-11. https://doi.org/10.1016/ 0378-1119(95)00676-1

27. Viviani, V. R., Bevilaqua, V. R., de Souza, D. R., Pelentir, G. F., Kakiuchi, M., \& Hirano, T. (2021). A very bright far-red bioluminescence emitting combination based on engineered railroad worm luciferase and $6^{\prime}$-amino-analogs for bioimaging purposes. International Journal of Molecular Sciences, 22(1), 1-13. https:// doi.org/10.3390/ijms22010303

28. Viviani, V. R., Gabriel, G. V. M., Bevilaqua, V. R., Simões, A. F., Hirano, T., \& Lopes-de-Oliveira, P. S. (2018). The proton and metal binding sites responsible for the $\mathrm{pH}$-dependent green-red bioluminescence color tuning in firefly luciferases. Scientific Reports, 8(1), 1-14. https://doi.org/10.1038/s41598-018-33252-x

29. Viviani, V. R., Amaral, D. T., Neves, D. R., Simões, A., \& Arnoldi, F. G. C. (2013). The luciferin binding site residues C/ T311 (S314) influence the bioluminescence color of beetle luciferases through main-chain interaction with oxyluciferin phenolate. Biochemistry, 52(1), 19-27. https://doi.org/10.1021/bi300740y

30. DeLucaf, M. (1969). Hydrophobic nature of the active site of firefly luciferase. Biochemistry, 8(1), 160-166. https://doi.org/10. 1021/bi00829a023

31. Viviani, V. R., Okawachi, F. M., Scorsato, V., \& Abdalla, F. C. (2008). CCD imaging of basal bioluminescence in larval fireflies: Clues on the anatomic origin and evolution of bioluminescence. Photochemical and Photobiological Sciences, 7(4), 448-452. https://doi.org/10.1039/b718016k

32. Roda, A., Guardigli, M., Michelini, E., \& Mirasoli, M. (2009). Bioluminescence in analytical chemistry and in vivo imaging. TrAC-Trends in Analytical Chemistry, 28(3), 307-322. https:// doi.org/10.1016/j.trac.2008.11.015

33. Viviani, V. R., \& Ohmiya, Y. (2006). Beetle luciferases: Colorful lights on biological processes and diseases. Photoproteins in bioanalysis (pp. 49-63). Wiley-VCH Verlag GmbH \& Co. KGaA. https://doi.org/10.1002/3527609148.ch3

34. Silva Neto, A. J., Scorsato, V., Arnoldi, F. G. C., \& Viviani, V. R. (2009). Pyrearinus termitilluminans larval click beetle luciferase: Active site properties, structure and function relationships and comparison with other beetle luciferases. Photochemical and Photobiological Sciences, 8(12), 1748-1754. https://doi.org/10. 1039/b9pp00053d

35. Niwa, K., Ichino, Y., Kumata, S., Nakajima, Y., Hiraishi, Y., Kato, D. I., Viviani, V. R., \& Ohmiya, Y. (2010). Quantum yields and kinetics of the firefly bioluminescence reaction of beetle luciferases. Photochemistry and Photobiology, 86(5), 1046-1049. https://doi.org/10.1111/j.1751-1097.2010.00777.x

36. Viviani, V. R., Bechara, E. J. H., \& Ohmiya, Y. (1999). Cloning, sequence analysis, and expression of active Phrixothrix railroadworms luciferases: Relationship between bioluminescence spectra and primary structures. Biochemistry, 38(26), 8271-8279. https:// doi.org/10.1021/bi9900830 
37. Buckley, S. M., Delhove, J. M., Perocheau, D. P., Karda, R., Rahim, A. A., Howe, S. J., Ward, N. J., Birrell, M. A., Belvisi, M. G., Arbuthnot, P., \& Johnson, M. R. (2015). In vivo bioimaging with tissue-specific transcription factor activated luciferase reporters. Scientific Reports, 5(1), 1-13. https://doi. org/10.1038/srep11842

38. Viviani, V. R., Silva, J. R., Amaral, D. T., Bevilaqua, V. R., Abdalla, F. C., Branchini, B. R., \& Johnson, C. H. (2020). A new brilliantly blue-emitting luciferin-luciferase system from Orfelia fultoni and Keroplatinae (Diptera). Scientific Reports, 10(1), 1-15. https://doi.org/10.1038/s41598-020-66286-1

39. Kim, Y. P., Daniel, W. L., Xia, Z., Xie, H., Mirkin, C. A., \& Rao, J. (2010). Bioluminescent nanosensors for protease detection based upon gold nanoparticle-luciferase conjugates. Chemical Communications, 46(1), 76-78. https://doi.org/10.1039/ b915612g

40. Chen, L., Chen, L., Dotzert, M., Melling, C. W. J., \& Zhang, J. (2017). Nanostructured biosensor using bioluminescence quenching technique for glucose detection. Journal of Nanobiotechnology, 15(1), 1-9. https://doi.org/10.1186/s12951-017-0294-1

41. Raoof, M., Zhu, C., Kaluarachchi, W. D., \& Curley, S. A. (2012). Luciferase-based protein denaturation assay for quantification of radiofrequency field-induced targeted hyperthermia: Developing an intracellular thermometer. International Journal of Hyperthermia. https://doi.org/10.3109/02656736.2012.666318

42. Noori, A. R., Hosseinkhani, S., Ghiasi, P., Akbari, J., \& Heydari, A. (2014). Magnetic nanoparticles supported ionic liquids improve firefly luciferase properties. Applied Biochemistry and Biotechnology, 172(6), 3116-3127. https://doi.org/10.1007/ s12010-014-0730-8

43. Ebrahimi, M., Hosseinkhani, S., Heydari, A., \& Akbari, J. (2015). Simple and rapid immobilization of firefly luciferase on functionalized magnetic nanoparticles; a try to improve kinetic properties and stability. Biomacromolecular Journal, 1(1), 104-112. Retrieved from www.bmmj.org

44. Käkinen, A., Ding, F., Chen, P., Mortimer, M., Kahru, A., \& Ke, P. C. (2013). Interaction of firefly luciferase and silver nanoparticles and its impact on enzyme activity. Nanotechnology, 24(34), 345101. https://doi.org/10.1088/0957-4484/24/34/345101

45. Abhijith, K. S., Sharma, R., Ranjan, R., \& Thakur, M. S. (2014). Facile synthesis of gold-silver alloy nanoparticles for application in metal enhanced bioluminescence. Photochemical and Photobiological Sciences, 13(7), 986-991. https://doi.org/10.1039/c4pp0 $0046 \mathrm{c}$

46. Rahme, K., Chen, L., Hobbs, R. G., Morris, M. A., O'Driscoll, C., \& Holmes, J. D. (2013). PEGylated gold nanoparticles: Polymer quantification as a function of PEG lengths and nanoparticle dimensions. RSC Advances, 3(17), 6085-6094. https://doi.org/10. 1039/c3ra22739a

47. Fu, Y., Feng, Q., Shen, Y., Chen, M., Xu, C., Cheng, Y., \& Zhou, X. (2018). A feasible strategy for self-assembly of gold nanoparticles: Via dithiol-PEG for photothermal therapy of cancers. RSC Advances, 8(11), 6120-6124. https://doi.org/10.1039/c7ra12735a

48. Liu, X.-Y., Wang, J.-Q., Ashby, C. R., Zeng, L., Fan, Y.-F., \& Chen, Z.-S. (2021). Gold nanoparticles: Synthesis, physiochemical properties and therapeutic applications in cancer. Drug Discovery Today. https://doi.org/10.1016/j.drudis.2021.01.030

49. Corbierre, M. K., \& Lennox, R. B. (2005). Preparation of thiolcapped gold nanoparticles by chemical reduction of soluble $\mathrm{Au}(\mathrm{I})-$ thiolates. Chemistry of Materials, 17(23), 5691-5696. https://doi. org/10.1021/cm051115a

50. Corbierre, M. K., Cameron, N. S., Sutton, M., Mochrie, S. G. J., Lurio, L. B., Rühm, A., \& Lennox, R. B. (2001). Polymerstabilized gold nanoparticles and their incorporation into polymer matrices [13]. Journal of the American Chemical Society, 123(42), 10411-10412. https://doi.org/10.1021/ja0166287
51. Corbierre, M. K., Cameron, N. S., \& Lennox, R. B. (2004). Polymer-stabilized gold nanoparticles with high grafting densities. Langmuir, 20(7), 2867-2873. https://doi.org/10.1021/la0355702

52. Rosenthal, E. Q., Puskas, J. E., \& Wesdemiotis, C. (2012). Green polymer chemistry: Living dithiol polymerization via cyclic intermediates. Biomacromolecules, 13(1), 154-164. https://doi.org/10. 1021/bm201395t

53. Majzik, A., Fülöp, L., Csapó, E., Bogár, F., Martinek, T., Penke, B., Bíró, G., \& Dékány, I. (2010). Colloids and surfaces B: Biointerfaces functionalization of gold nanoparticles with amino acid, $\beta$-amyloid peptides and fragment. Colloids and Surfaces $B$ : Biointerfaces, 81(1), 235-241. https://doi.org/10.1016/j.colsurfb. 2010.07.011

54. Kawai, C., Prado, F. M., Nunes, G. L. C., Di Mascio, P., CarmonaRibeiro, A. M., \& Nantes, I. L. (2005). pH-dependent interaction of cytochrome $\mathrm{c}$ with mitochondrial mimetic membranes: The role of an array of positively charged amino acids. Journal of Biological Chemistry. https://doi.org/10.1074/jbc.M412532200

55. Menezes, L. R., Sombrio, G., Costa, C. A., Bronzato, J. D., Rodrigues, T., Souza, J. A., \& Nantes-Cardoso, I. L. (2019). Nanostructured hematite decorated with gold nanoparticles for functionalization and biocompatibility. Physica Status Solidi (A) Applications and Materials Science. https://doi.org/10.1002/pssa. 201900589

56. Girardi, L., Shuang, S., Rizzi, G. A., Sartorel, A., Marega, C., Zhang, Z., \& Granozzi, G. (2018). Visible light driven photoanodes for water oxidation based on novel $\mathrm{r}-\mathrm{GO} / \beta-\mathrm{Cu} 2 \mathrm{~V} 2 \mathrm{O} 7 / \mathrm{TiO} 2$ nanorods composites. Nanomaterials, 8(7), 544. https://doi.org/ 10.3390/nano8070544

57. Calmon, M. F., de Souza, A. T., Candido, N. M., Raposo, M. I. B., Taboga, S., Rahal, P., \& Nery, J. G. (2012). A systematic study of transfection efficiency and cytotoxicity in HeLa cells using iron oxide nanoparticles prepared with organic and inorganic bases. Colloids and Surfaces B: Biointerfaces, 100, 177-184. https:// doi.org/10.1016/J.COLSURFB.2012.05.026

58. Barreto, G. R., Kawai, C., Tofanello, A., Neves, A. A., AraujoChaves, J. C., Belleti, E., Lanfredi, A. J., Crespilho, F. N., \& Nantes-Cardoso, I. L. (2019). Magnetoliposomes as model for signal transmission. Royal Society Open Science, 6(1), 181108. https://doi.org/10.1098/rsos.181108

59. Kamnev, A. A., Dykman, L. A., Tarantilis, P. A., \& Polissiou, M. G. (2002). Spectroimmunochemistry using colloidal gold bioconjugates. Bioscience Reports, 22(5-6), 541-547. https://doi.org/10. 1023/A:1022077920527

60. López-Lorente, Á. I., Sieger, M., Valcárcel, M., \& Mizaikoff, B. (2014). Infrared attenuated total reflection spectroscopy for the characterization of gold nanoparticles in solution. Analytical Chemistry, 86(1), 783-789. https://doi.org/10.1021/ac403284f

61. Viviani, V. R., Simões, A., Bevilaqua, V. R., Gabriel, G. V. M., Arnoldi, F. G. C., \& Hirano, T. (2016). Glu311 and Arg337 stabilize a closed active-site conformation and provide a critical catalytic base and countercation for green bioluminescence in beetle Luciferases. Biochemistry, 55(34), 4764-4776. https://doi.org/10. 1021/acs.biochem.6b00260

62. Yokomizo, C. H., Pessoto, F. S., Prieto, T., Cunha, R. L. O. R., \& Nantes, I. L. (2015). Effects of Trichlorotelluro-dypnones on mitochondrial bioenergetics and their relationship to the reactivity with protein thiols. Chemical Research in Toxicology, 28(6), 1167-1175. https://doi.org/10.1021/tx5005166

63. Park, J.-E., Kim, J., \& Nam, J.-M. (2017). Emerging plasmonic nanostructures for controlling and enhancing photoluminescence. Chemical Science, 8(7), 4696-4704. https://doi.org/10.1039/ C7SC01441D

64. Ribeiro, C., \& Esteves Da Silva, J. C. G. (2008). Kinetics of inhibition of firefly luciferase by oxyluciferin and 
dehydroluciferyl-adenylate. Photochemical and Photobiological Sciences, 7(9), 1085-1090. https://doi.org/10.1039/b809935a

65. Da Silva, L. P., \& Esteves Da Silva, J. C. G. (2011). Kinetics of inhibition of firefly luciferase by dehydroluciferyl-coenzyme A, dehydroluciferin and 1-luciferin. Photochemical and Photobiological Sciences, 10(6), 1039-1045. https://doi.org/10.1039/ c0pp00379d
66. DeLuca, M., \& McElroy, W. D. (1974). Kinetics of the firefly luciferase catalyzed reactions. Biochemistry, 13(5), 921-925. https://doi.org/10.1021/bi00702a015

67. Chavanis, P. H. (2019). Generalized Euler, Smoluchowski and Schrödinger equations admitting self-similar solutions with a Tsallis invariant profile. European Physical Journal Plus, 134(7), 353. https://doi.org/10.1140/epjp/i2019-12706-y 